\title{
Reinventando a roda: inversões e reversões de uma antropografia do sujeito
}

\section{Scott Head}

Universidade Federal de Santa Catarina, Florianópolis, Brasil

E-mail:head.sc@gmail.com 


\section{Resumo}

Este artigo toma como seu ponto de partida o "princípio da roda" tal como elaborado por Roy Wagner em $A n$ Anthropology of the Subject (2001): ao "reinventar" uma roda - ou outro objeto -, reinventa-se igualmente o sujeito que realiza a invenção. Mas, nesse caso, trata de deslocar essa figura reflexiva rumo a uma outra "roda" estranhamente semelhante - certa roda popular de capoeira, tal como descrita no livro Capoeiragem: expressões da Roda Livre, de Mestre Russo de Caxias (2005). Ao tomar tal livro como o enfoque deste ensaio, ressalta-se como seu autor, ao descrever e inventar a roda a que seu livro diz respeito, acaba sendo reinventado, ele mesmo, pela roda - e jogo - em questão. Mas, ao buscar compreender tal processo de invenção e contrainvenção, o próprio desdobrar deste texto que segue também passa a ser "compreendido" por esse seu objeto: pensar sobre a roda através do livro de Mestre Russo e sobre ambos através de Wagner instiga uma reflexão sobre o ato de escrever e compor na forma de imagens. E, desse modo, a relação assim ensaiada passa a ressaltar algumas claras diferenças - e estranhas semelhanças com respeito aos modos de compor e de compreender, de textualizar e de contextualizar, os 'sujeitos' etnográficos da antropologia.

Palabras-clave: Reflexividade. Capoeira. Roy Wagner. Imagem. Representação etnográfica. Sujeito.
Abstract

This article takes as its point of departure the "wheel principle" as elaborated by Roy Wagner in An Anthropology of the Subject (2001): in 'reinventing' a wheel - or other object, the subject doing the inventing ends up reinventing him - or herself as well. Only here, the reflexive figure in question shifts towards an apparently quite different yet strangely similar "wheel" - in this case the rounded space of a certain popular "roda" of capoeira (an Afro-Brazilian danced martial art form played to musical accompaniment), as described in the book, Capoeiragem: expressões da Roda Livre, by Mestre Russo de Caxias. In taking such a book as its focus, this essay foregrounds how its author, in describing and inventing the "wheel-like" game, ends up himself being 'reinvented' by the very game of which he writes. But in seeking to comprehend this process of invention and counterinvention, the unfolding of the very essay that follows also gets caught up in and 'comprehended' by the very wheel-like process it takes to be its object of analysis: thinking about the roda through Mestre Russo's book and thinking about both through Wagner instigates a reflection on the act of writing and composing in the form of images. And, in this way, the relation thus elaborated points to some clear differences - and strange similarities - with respect to the modes of composing and comprehending, of textualizing and contextualizing, the ethnographic 'subjects' of anthropology.

Keywords: Reflexivity. Capoeira. Roy Wagner. Image. Ethnographic Representation. Subject. 
i was made to believe we who write also dance yet no dancer writes

(the way we write) no writer ever dances (the way they dance) $^{1}$

'roda' ao redor da qual este ensaio se desloca rodou um tanto
longe daquela com a qual Roy Wagner inicia seu capítulo com o mesmo título - "Reinventing the Wheel" - em An Anthropology of the Subject (Wagner, 2001, p. 191): “The wheel rolls into history under the armored wagons of the early Babylonians and the carts and chariots of Eurasian wanderers and conquerors". No caso aqui considerado, tanto a 'roda' quanto a direção em que ela roda para dentro da história sofrem um duplo desvio de sentido: primeiramente, por dizer respeito a uma roda de capoeira - um desvio efetuado no plano da tradução; e segundo, por tal roda 'rodar' num sentido distinto daquelas que sustentam o movimento das carroças referidas acima. Pois, se uma roda de capoeira também envolve movimento concêntrico, seu ângulo de rotação em relação ao chão em que se desloca é inerentemente variável, diferindo assim da fixação perpendicular das rodas naquelas carroças, que limitava o deslocamento para frente (ou para trás) desses veículos de conquista e de comércio - deslocamentos que propulsionaram, por sua vez, os avanços (e retrocessos) da própria “história" referida por Wagner.

O movimento de uma roda de capoeira assemelha-se mais ao movimento de um torno, só que nesse caso a 'argila' sendo modela- 
da consiste nos próprios corpos que brincam e lutam dançando na roda - corpos que se deslocam não apenas para frente ou para trás, mas igualmente para os lados e até para cima e para baixo. Assim, o movimento envolvido nessa forma singular de roda sugere outra imagem da história que aquela das carroças - uma imagem em tudo menos linear, 'progressiva' ou 'regressiva'. Ao mesmo tempo, tal movimento assemelha-se bem às múltiplas circunlocuções tanto físicas quanto cosmológicas da roda, tal como reinventada no desdobrar do texto de Wagner a seu respeito. Pois a 'roda', tal como conceituada naquele capítulo, envolve igualmente o processo de compreender tal roda - ou, por extensão, qualquer outra coisa compreendida através do "wheel principle" ou princípio da roda: "One can only grasp or comprehend things to the extent that one's process in doing so is itself grasped or comprehended by them" (Wagner, 2001, p. 202). Desse modo, ao tomar 'a roda' como o objeto desse princípio, que por sua vez envolve tanto o processo de compreensão quanto o mundo que compreende esse processo, Wagner volta-se para o sujeito que faz tal objeto rodar: "Neither the wheel itself nor that simplification by which we have come to know and use its properties exists independently of human thought and conception" (p. 204). Ou seja, ao "reinventar a roda", reinventa-se igualmente o sujeito que realiza a invenção. Como veremos, tal processo analógico (e circular) estende-se igualmente à reinvenção da roda de capoeira de que se trata neste ensaio.

Desse modo, chegamos a um terceiro desvio de sentido envolvido no tecer deste diálogo entre as ideias de Wagner e a "roda" aqui tomada como objeto: não se trata da roda de capoeira 'em si', mas de uma roda tal como descrita e composta no livro popular ${ }^{2}$ Capoeiragem: expressões da Roda Livre (Russo de Caxias, 2005). Trata-se desse livro, mais especificamente, tal como escrito, composto e publicado por conta própria por seu autor, Mestre Russo de Caxias. Ao tomar tal livro como o enfoque deste ensaio, busco ressaltar como seu autor, ao inventar a roda a que seu livro diz respeito, acaba sendo reinventado, ele mesmo, pela roda - e jogo - em questão. Mas, à medida que busco compreender tais processos de invenção e contrainvenção, 
minha leitura também passa a ser compreendida por esse meu objeto: pensando através do livro de Mestre Russo, o livro me faz pensar de outro modo sobre o próprio ato de escrever sobre ele. E, desse modo, ao escrever sobre tal livro, a relação assim ensaiada passa a ressaltar algumas claras diferenças - e estranhas semelhanças - com respeito aos nossos modos de compor e de compreender, de textualizar e de contextualizar, os 'sujeitos' da antropologia. Ou seja, tomar o livro como o objeto deste ensaio desloca a roda da compreensão da "antropologia do sujeito" de Wagner rumo a uma antropografia (Dumont, 1986) desse sujeito - nesse caso, do sujeito tal como roda entre essas duas formas de escrever. ${ }^{3}$

Aproximado ou contornado desse modo, o livro de Mestre Russo oferece um modo um tanto singular de tratar do problema básico da "anthropological reportage", tal como estipulado no prefácio de $A n$ Anthropology of the Subject (Wagner, 2001, p. xi): “o fato que nenhuma perspectiva teórica em particular, mesmo combinada com outras, pode ser usada efetivamente para obter um domínio sobre o sujeito antropológico". ${ }^{4}$ É evidente que a 'antropologia do sujeito' não é um tema novo, ${ }^{5}$ mas o apelo da abordagem de Wagner consiste justamente em não pressupor, enquadrar ou sujeitar o 'sujeito' de antemão: os saltos constantes do livro entre coisas e conceitos, parecendo abordar 'quase tudo' menos o que convencionalmente enquadraríamos como sujeitos, nos demonstram amplamente o valor de tal indefinição premeditada. Não é que devamos dispensar todo tipo de enquadre: Bateson (1972) já nos mostrou o quão importantes esses são mesmo em atividades tão pretensamente 'livres' como brincadeiras e fantasias. Mas o que importa aqui é como tais enquadres instigam composições inusitadas entre os sujeitos em questão.

Mesmo assim, a pergunta permanece: o que é um 'sujeito antropológico'? Ou, antes disso, o que é um 'sujeito', afinal? De modo geral, as 'definições' que Wagner nos oferece no 'Glossário de conceitos não familiares' do final de seu livro gozam da própria busca de definições 'claras e distintas' que teria nos levado a consultar tal glossário: certamente não é um glossário cartesiano. Ainda assim, as três definições que Wagner oferece a respeito do 'sujeito', do 'sujeito ati- 
vo' e do 'sujeito da antropologia' parecem relativamente claras em si e entre si, comparadas a várias outras que constam no glossário: começa-se com o sujeito "[...] sujeitado ou contra-face sub-determinada da agencia"; procede-se ao sujeito como "ponto da ação", com "a potência [...] de inverter" o caráter passivo do primeiro sujeito; e chegamos, por fim, ao "conhecimento humano daquilo que a condição humana pode ser [...] como se uma síntese fosse possível" (Wagner, 2001, p. 254). Até aqui, tudo bem (será?). Mas, traduzidos e resumidos desse modo um tanto 'sintético', arriscamos perder justamente o humor nos detalhes e os detalhes do humor, tanto aqui como na composição do livro, que constantemente nos desviam de uma compreensão linear - detalhes que nos lembram, entre outras coisas, justamente da dimensão subjuntiva da suposição, "como se uma síntese fosse possível". Ou seja, o próprio modo como Wagner nos apresenta o 'sujeito' em questão já sugere que, se fôssemos dissociar as questões sérias a seu respeito do humor como são comunicadas na sua escrita, arriscaríamos torná-las uma piada às nossas custas - às custas, no caso, da própria vitalidade da antropologia do 'sujeito' implicada no seu modo de escrever.

Passando dessa brevíssima introdução ao sujeito no livro de Wagner, o que de fato envolveu apenas um salto de seu prefácio ao seu glossário como apresentado, pulando por cima do corpo do livro em si, passo à seguinte afirmação a ser elaborada aqui: se o 'sujeito' da antropologia for estendido para a 'antropologia' daquele assim sujeitado, então o livro de Mestre Russo e o 'Mestre Russo' desse livro podem juntos nos levar a uma outra compreensão desse 'nosso' sujeito. E, no caso considerado aqui, sugiro que a relação entre o livro e seu autor seja uma função do duplo movimento entre o sentido do movimento e o movimento do sentido que ambos implicam de modos distintos com respeito ao movimento dos corpos na roda de capoeira. Ou, pelo menos, é através dessa figuração cinestética que busco traçar a relação entre a roda de capoeira, tal como compreendida através do livro de Mestre Russo, e a roda da compreensão, tal como figurada por Wagner. 
Desse modo, a próxima seção diz respeito ao problema da autorreferência: se um dos principais fatores que fazem um 'texto' diferir do 'discurso' é a separação dos signos fixados no texto do elo direto com o sujeito de enunciação (Geertz, 1973; Ricoeur, 1971), mesmo assim, indícios desse sujeito-tornado-autor permanecem no texto (Fernandez, 1985). No caso em questão, encontramos tais indícios não só nas palavras escritas por Mestre Russo, mas no seu próprio nome, assim como em imagens fotográficas e até em citações de outros mestres que fazem parte igualmente do texto em questão.

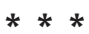

Logo nas primeiras frases da Apresentação de seu livro, Mestre Russo de Caxias afirma:

Este livro foi escrito para proporcionar ao leitor informações relevantes sobre a história da capoeira em Duque de Caxias. Nesse volume serão encontrados fatos que me consolidaram como pessoa e que me deram estrutura suficiente para fazer da minha vivência na capoeiragem uma história que se revela em forma de documentário (2005, p. 10).

Repara-se aqui como os dois 'sujeitos' em questão - Mestre Russo e a própria capoeira - estão claramente emaranhados; claramente, pois só seria 'confuso' se fôssemos pressupor a distinção entre eles. Repara-se igualmente no uso da primeira pessoa, mas na forma passiva - são os próprios fatos que "me consolidaram como pessoa e que me deram estrutura": ao mesmo tempo que o texto assim se coloca de um modo mais autobiográfico do que biográfico, deslocase a presença do 'eu' para além do sujeito ativo da frase. Em certa medida, isso lembra a convenção etnográfica de minimizar a presença do 'eu' que escreve, incluindo tais indícios do etnógrafo no texto apenas na medida em que autenticam os 'fatos' consolidados no campo, mas sem tornar o próprio etnógrafo o sujeito da etnografia. Igualmente lembra certas experimentações etnográficas associadas à antropologia dita 'pós-moderna' - experimentos que, ao mesmo tempo que tanto criticam quanto brincam com as convenções da escrita

\section{ILHA}

volume 12 - número 1 
etnográfica, arriscam acabar mitificando o "antropólogo como herói" (Kapferer, 1988).

Além do modo de escrever em si, encontramos outros indícios do deslocamento do autor como sujeito central e ativo do livro. Evidentemente, tais indícios móveis destacam-se contra o fundo de autoposicionamentos mais convencionais, como no caso do retrato 'close-up' do rosto em perfil de Mestre Russo na capa de trás do livro: ao mesmo tempo que tal foto segue a convenção de mostrar a visagem do autor do livro, seus olhos ficam ocultos pela sombra de seu chapéu de palha estilo panamá - um chapéu bastante comentado, aliás, como parecendo "ser fundido à sua cabeça, por nunca cair na hora do jogo" (Nunes, 2004 apud Russo de Caxias, 2005, p. 127). Tal retrato, pelo viés da conjugação imagética do ditado que diz que os olhos são a 'janela da alma' com a visagem impenetrável do bom malandro carioca ressaltada pela sombra do chapéu, nos faz perceber a própria ocultação de seu olhar como se revelasse sua 'alma' de capoeirista, pois o que seria um capoeirista sem malandragem? (E o que seria um malandro sem seu chapéu?)

Virando o livro para sua capa de frente, o próprio nome do autor, Mestre Russo de Caxias - que é tudo menos um 'nome próprio' -, oferece outra face desse deslocamento do autor como um ser-emmovimento. Percebe-se aqui como marcas do outro 'sujeito' do livro - "a história da capoeira em Duque de Caxias" - já estão inscritas nesse nome, marcas tanto da prática como do lugar: 'Mestre' e 'Caxias'. Já o nome que sobra, 'Russo', implica algo mais (ou menos) do que o 'individuo' por trás desses títulos sociais ou a fonte da individuação dessas marcas. Como constatamos na legenda de uma foto que encontramos duas páginas antes da Apresentação do autor, de "Jonas 'Russo' Rabelo" e seus irmãos quando meninos, este nome, Russo, é ele mesmo um apelido. Curiosamente, nessa foto que mostra os quatro irmãos sentados em frente à entrada de uma casa, quem menos aparece é o próprio Russo; devido à sua sobre-exposição na foto, é como se a luz atravessasse seu corpo. Mas, ao voltarmos umas folhas atrás para a página da Dedicatória, encontramos uma solução possível para a charada que a escolha dessa imagem borrada do au- 
tor nos apresenta. Pois aqui, nas palavras dirigidas a seu primo, o 'Crioulo', consta que esse primo é "a pessoa que me deu iniciação na capoeira e incentivo para eu continuar como capoeirista, tornando a arte do jogo a essência da minha alma" (2005, p. 4). Ou seja, levando essas palavras a sério, podemos imaginar que, naquela foto, 'Russo' ainda não havia adquirido a essência daquilo que viria a defini-lo como 'pessoa' - e desse modo daria substância a seu corpo.

Mesmo deixando de lado tal leitura como mera 'brincadeira' da minha parte, essa e outras referências à capoeira como consistindo na sua própria 'alma' sugerem que os 'títulos sociais' de 'Mestre' e 'Caxias', que agora fazem parte de seu nome como autor e pessoa, são algo mais do que índices contextualizantes das conexões ou dos compromissos com a prática e o lugar que o definem como uma pessoa social. A substituição desses honoríficos no lugar de seu nome e sobrenome, Jonas e Rabelo, deixando apenas o apelido no meio como laço de continuidade, passa assim a sugerir que "sua mais constante natureza" - voltando a citar Wagner (1981, p. 139; 2010a, p. 213 ) - "não é a de ser mas a de devir". Pois, se formos seguir o processo de substituição de seus nomes, reparamos o seguinte: primeiro, 'Russo' figura como o apelido contra o fundo de seu nome e sobrenome - Jonas e Rabelo; mas, com a substituição eventual desses nomes por 'Mestre' e 'de Caxias', Russo agora assume o lugar de fundo contra essas figuras - ao mesmo tempo que essas figuras estendem-se e assim estendem o próprio Russo a outros fundos ou 'contextos'.

Evidentemente, tal substituição de nomes, por si só, poderia ser tomada como mera mudança na superfície da pessoa 'pública' que não necessariamente afeta a substancialidade do 'eu' em questão. Mas aqui o termo 'mestre' não se refere apenas a uma posição hierárquica e institucional a ser 'ocupada' por dados indivíduos, mas a "algo corporificado e encarnado, se quiserem, na pessoa" (Turner, 2005, p. 146-147). Ou seja, o título de mestre implica uma "mudança ontológica" (p. 147) efetuada por um longo processo de aprendizagem ritualizado através dos anos, o que se trata não da "mera aquisição de conhecimento, mas de uma mudança no ser" (p. 147). E o que mais importa aqui é que encontramos indícios indiretos dessa mudança no livro. 
Voltando à questão da 'alma' de Mestre Russo e dos indícios a seu respeito que constam no livro de sua autoria, importa notar a citação no livro de um ditado de um dos principais 'ancestrais' da capoeira - tido por muitos como o principal convencionalizador do estilo 'tradicional' da Capoeira Angola. O ditado encontra-se numa seção do livro chamada "Rememorando Mestre Pastinha", que consta, por sua vez, como parte de uma série de outras 'rememorações', todas de antigos mestres reconhecidos como ancestrais da capoeira - exceto, talvez, a última, chamada "Rememorando Jorge Amado". As 'rememorações' não seguem uma ordem cronológica, se bem que todas começam com referências à data de nascimento do mestre sendo rememorada, uma convenção biográfica que só não é utilizada para o próprio autor, cuja referência à sua data de nascimento (1956) só encontramos na penúltima seção do livro, "Sobre o autor", mais um indício do deslocamento enigmático do sujeito em questão. Mas agora passo à citação do ditado de Mestre Pastinha: “O capoeirista não é aquele que sabe movimentar o corpo, mas sim, aquele que deixa o corpo ser movimentado pela sua alma" (Pastinha apud Russo de Caxias, 2005, p. 40).

Uma vez que, em sua dedicatória ao primo, Mestre Russo já havia afirmado que "a arte do jogo" consistia na "essência" de sua alma, levar ambas essas afirmações a sério implica que a alma que movimenta seu corpo no jogo é o próprio jogo tornado alma. Sem buscar explicar ou fixar o movimento da alma do autor em questão, apenas acrescento uma hipótese. Apropriando os termos encenados nas 'conversas' entre Wagner e o coiote em Coyote Anthropology (2010b), pergunto se o devir implicado no próprio nome de Mestre Russo de Caxias e estendido nas suas rememorações de outros mestres e personagens envolve menos a personificação ("impersonation") de certa identidade sociocultural do que a ex-personificação ("expersonation") de sua alma como uma alma-em-movimento que, desse modo, menos "se rememora" através das referências aos outros mestres do que se prolifera a partir dessas variadas incorporações ancestrais da alma da capoeira. 
De todo modo, termino esta primeira seção com um último indício do movimento enigmático que se realiza no livro através do deslocamento de certas convenções com as quais se costuma posicionar o autor como sujeito central do livro. Ainda antes da foto borrada de Russo como menino, encontramos um retrato mais formal, dessa vez de um adulto cuja barba branca já sugere certa idade. Só que esse retrato, que assume um lugar de destaque na página logo depois daquela do título, não é do autor do livro, mas, como diz na legenda, consiste num retrato do "autor da pintura da capa do livro". Mas, antes de voltar àquela capa, desvio nossa atenção primeiro para a imagem da capa de um outro livro.

\section{$* * *$}

Trata-se, no caso, de uma imagem ausente - ausente da capa de A invenção da cultura (Wagner, 2010a), tal como traduzido e publicado no Brasil. A imagem em questão, presente na capa original do livro publicado em inglês, consiste na litografia bastante familiar de Maurits Escher, Drawing Hands. Deixo o título em inglês, no caso, porque só quando fui traduzi-lo me dei conta de que, como ele repete em palavras a própria duplicidade singular da imagem, teria que traduzi-lo em algo como Desenhando mãos e Mãos que desenham - ao mesmo tempo. Mesmo em inglês, portanto, para ler o título conforme a figuração da imagem, teria que ler ambos os significados como que simultaneamente. De fato, poderia ser dado o título Mãos que se desenham, o que em inglês seria Hands Drawing Themselves, mas, desse modo, perderia justamente o paradoxo no cerne da imagem. Ou seja, só traduzindo 'errado' daria certo, mas nesse caso dando certo perderia a graça.

Mas por que nos determos nessa imagem? Na verdade, quando reparei sua ausência na capa de $A$ invenção da cultura no Brasil, logo associei tal mudança a um aspecto um tanto recorrente na recepção em geral bastante inspirada das ideias de Roy Wagner no Brasil: no caso, a tendência de contrapor Wagner aos proponentes de uma antropologia dita 'pós-moderna'. Pois eu vi a imagem de Escher em 
questão como se referindo a um ato comumente associado a esta vertente teórica da antropologia - o ato de escrever; não é por acaso que o título da principal obra referida nas críticas da 'antropologia pós-moderna' no Brasil é Writing Culture (Clifford e Marcus, 1986). Só que, em algum momento, me dei conta de algo que talvez teria sido óbvio desde já se não fosse essa minha reação à figuração contrastante de Wagner: que, no caso, o desenho de Escher não trata propriamente do ato de escrever, mas sim de desenhar. Portanto, a motivação inicial por trás da minha referência à imagem ausente se desfez.

Ainda bem! Pois foi através dessa minha 'falha' na percepção da imagem que passei a reparar que é justamente nisso que consiste o aspecto singular de Wagner com respeito à problemática do escrever da antropologia: ele menos escreve do que desenha com palavras - e as figurações que ele assim traça assemelham-se de certo modo a essa do Escher. A esse respeito, Tim Ingold (2007, p. 3) oferece certo fundo antropológico para essa figuração, ao ressaltar tanto as continuidades quanto as diferenças entre esses modos:

Enquanto o escrever for entendido em seu sentido original como uma prática de inscrição, não pode haver nenhuma concreta distinção entre escrever e desenhar [...]. Na digitação e impressão, é quebrado o laço íntimo entre o gesto manual e o traço que inscreve. O autor conduz o sentimento por sua escolha de palavras, não pela expressividade de suas linhas.

No caso do Wagner, o modo como ele articula suas palavras e compõe seus conceitos $\mathrm{e}(\mathrm{m})$ seus textos introduz figuras recursivas no fluir do argumento de que são tudo menos 'floreios' ou 'embelezamentos' às proposições teóricas e aos dados etnográficos oferecidos.

Vejamos, por exemplo, sua discussão das formas de inscrição iconográfica do povo Walbiri na Austrália Central, descritas por Nancy Munn (1973 apud Wagner, 1986, p. 19-24), que dizem respeito tanto aos desenhos de pisadas que vários animais, assim como eles mesmos e seus ancestrais, deixam ao movimentar-se através da paisa- 
gem quanto às impressões deixadas na areia que acompanham os relatos orais dessas trajetórias. Como Wagner (1986, p. 21) comenta a respeito dessas múltiplas formas de rastro:

Pois um rastro representa a si mesmo como um microcosmo, como ser e movimento comprimidos em um plano bidimensional, e desta forma implica na incorporação mais plena deste ser e deste movimento como aquilo que fez o rastro.

Mais à frente, ele estende essa observação da seguinte forma:

[...] a dialética entre codificação microcósmica e produções estética sensorialmente ricas não é de forma alguma limitada aos walbiri, ou aos aborígines do deserto central. Ela é de fato a condição do simbolismo humano: uma polaridade ou contraste que opõe uma codificação simbólica artificialmente restrita a uma imagética icônica também artificialmente expandida (Wagner, 1986, p. 23).

É algo nesse sentido que sugiro quando digo que Wagner escreve "desenhando". De forma semelhante ao sentido figurado por esses rastros ou pela própria imagem de Escher, ambos implicam corpos de três dimensões, apesar de serem comprimidos em um plano de apenas duas. Mas como assim? Seu modo de pensar escrevendo e de escrever pensando não só representa ou se refere, mas - de certa forma - se assemelha às formas culturais por ele descritas. Apenas de certa forma, pois certamente não se trata de imitar tais formas, mas de criar uma relação analógica entre os fluxos de sua escrita e os processos de criação, convencionalização e subjetivação das formas 'nativas' em questão - inclusive as de sua 'própria' cultura. Digo isso no sentido de que seu modo de escrever tende a configurar ou dar corpo à dimensão não referencial, figurativa da linguagem, que tanto sustenta quanto desloca e inverte sua função referencial. Ele escreve com algo da duplicidade singular das palavras conjugadas do título da imagem: Drawing Hands. Ou seja, ao desenhar tais formas-em-movimento, ele tanto salta quanto ressalta as diferenças sendo traçadas - e a relação recursiva entre elas.

Ao mesmo tempo, Michael Taussig (2009, p. 270) comenta a respeito da conceituação do ato de desenhar de John Berger: “uma 
linha traçada é importante não tanto pelo que registra quanto pelo que te leva a ver". Seguindo nesse sentido, o escrever de Wagner também se refere a outros modos de figurar a linguagem e configurar o mundo ao redor, convertendo um no outro como se movimentando num laço torcido mas contínuo, apesar de seus nós - como os pontos dos lápis naquele desenho, onde tanto se articula à diferença entre o 'dentro' e o 'fora' quanto a desfaz, e onde o fim se encontra com o começo e o 'outro' começa onde o 'eu' acaba.

Tendo aberto esse longo parêntese teórico-figurativo referindo-me a uma imagem ausente da capa de $A$ invenção da cultura, fecho o parêntese referindo-me à imagem da capa de An Anthropology of the Subject (2001), que nesse caso consiste numa figura igualmente recursiva e autocriadora, só que essa se cria através de um relâmpago saindo de duas mãos, em vez do grafite deixado pelo lápis nas mãos de Escher - neste caso a figura foi desenhada pelo próprio autor do livro!

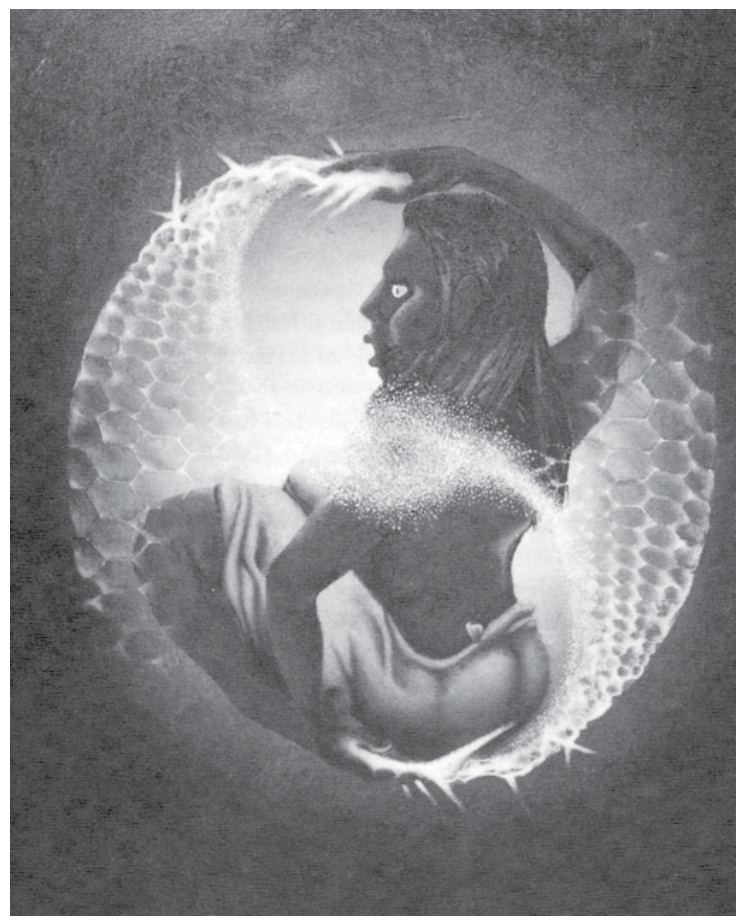

Figura 1 - A rede de Indra

Fonte: Wagner, 2001, p. 14 (desenhado pelo autor). 
Sem buscar ligar, por enquanto, essa discussão de volta ao 'sujeito' deste ensaio, volto nossa atenção há uns dez anos antes da publicação do livro de Mestre Russo. Voltamo-nos, no caso, à certa forma particular de roda que aconteceu no segundo andar do Sindicato dos Petroleiros no Centro do Rio de Janeiro, onde o grupo de Capoeira Angola ao qual eu pertencia praticava esse estilo dito 'tradicional' da capoeira. Com esse outro desvio busco elaborar um pouco do fundo etnográfico contra o qual a figura do livro de Mestre Russo de Caxias se destaca - se bem que não é tão simples assim.

No caso, estávamos sentados numa roda, só que não no chão, como seria o caso de uma roda de Capoeira (Angola), mas em cadeiras ao redor de uma 'mesa redonda' improvisada pelo agrupamento de várias mesinhas de escritório que havia na sala onde treinávamos capoeira três vezes por semana, mesas tipicamente empurradas para os cantos da sala para abrir espaço para treinar. Toda semana, naquela época (entre 1994 e 1996) e naquela sala cedida pelo Sindicato, treinávamos segundas, quartas e sextas durante duas ou até três horas, e fazíamos, uma vez por mês, uma 'roda de rua' na Praça da Cinelândia, no Centro do Rio de Janeiro. Periodicamente - também uma vez por mês em teoria, um pouco menos na prática -, nós substituíamos uma roda de capoeira por uma dessas rodas de leitura. Se bem que essas 'rodas' eram apenas uma versão mais formal das falas que se seguiam quase toda aula de capoeira - 'conversas' comumente consistindo mais propriamente num monólogo do mestre que se estendiam às vezes por mais de uma hora.

Ou seja, tanto a substituição 'ritualizada' da capoeira pela 'papoeira' - como costumávamos brincar - quanto o próprio deslocamento das mesinhas dos cantos da sala para compor a 'roda' no seu centro envolviam justamente uma inversão de figura e fundo, em que o discurso metacultural literalmente tomava o lugar da prática cultural da qual se falava a respeito ou ao redor.

Mas aqui as próprias conversas que se desdobraram nesses momentos também eram capazes de, se não reverter tais inversões, pelo menos tencionar ou vibrar as suas frestas - e, assim, permitir 
vislumbrar um ofuscar desses limites. Sem mais contextualização explícita da minha parte, deixe-me passar à 'transcrição direta' de uma dessas falas, apenas inserindo os nomes dos 'sujeitos' em questão. Nesse caso, faço uso dessa ficção objetivista de apresentar a fala em questão, pretensamente sem 'interferência' da minha parte (além de certas pequenas elisões do 'ruído' da oralidade), justamente para mostrar como a própria fala que segue acaba abalando essa pretensão.

João:

-É o seguinte: a gente tem escolhido alguns textos para fazer esses seminários de leitura. Esses textos têm um objetivo, que é ao mesmo tempo trabalhar e aprofundar a questão da capoeira [...] a gente entender um pouco mais sobre aquilo que nós estamos praticando, quer dizer, o que nós estamos treinando aqui dentro, e outros textos também, em que se encontra [...] que nos informam sobre a questão do negro no Brasil, sobre outros aspectos da cultura. E este texto agora, [...] que dá uma introdução geral, apesar de ter uns erros, mas dá uma visão da capoeira, comparando a capoeira Angola com Regional [...].

Daniela:

- Quais são os erros que tem neste texto?

João:

-É porque tem uma parte aqui onde fala que João Grande e João Pequeno foram alunos do Mestre Bimba [...]. Sacanagem, né? Eu não sei se isso foi na hora de copiar ou se entendeu errado, mas nenhum desses dois foi aluno do Bimba.

Baba:

- Essa falha, esse tipo de falha ocorre. Quem não conhece direito a história quer falar coisas que não sabe então puxa a imaginação com esse tipo de falha. Isto é normal, a gente não tem que se espantar [...] com certas histórias que se ouve falar, ouviu dizer, não [...]. A gente nunca deve se impressionar com isso, que às vezes as pessoas escrevem certos textos nos jornais, às vezes até livros, que não têm nada a ver com a coisa genuinamente da Capoeira Angola. Não tem a ver. A gente tem que saber que [...] muita coisa que se tem escrita, milhões de livros, simplesmente se você pegar para ler profundamente, não tem nada a ver com capoeira - o cara não conhece nada de Capoeira Angola, ele é um curioso que simplesmente sabe falar meia dúzia de palavras de capoeira e

ILHA

volume 12 - número 1 
tem a cisma de achar que ele sabe - não sabe nada! Eu já presenciei vários contextos dessas pessoas que botam coisas escritas que não têm nada a ver, não manja nada, só o que um falou, o outro disse, e alguém concluiu para ele, mas saber a fundo, não sabe. Eu acho que a gente tem que saber que a consciência da Capoeira Angola, ela tem que ser sempre lida, na minha concepção, lida por quem gosta da capoeira, quem tem admiração, quem tem laços, eu não sei, fraternos ou espirituais com a capoeira [...].

Voltando-nos para o livro de Mestre Russo através da perspectiva afirmada acima por (atualmente, Mestre) Baba, na medida em que a grande maioria daquele livro consiste em citações das falas e de textos de outros praticantes e pesquisadores, ele poderia ser lido como exemplificando justamente o pior tipo de texto sobre capoeira - um daqueles 'milhões' de livros que apresentam "só o que um falou, o outro disse, e alguém concluiu para ele [...]". Ao mesmo tempo, Mestre Russo claramente sabe falar bem mais do que "meia dúzia de palavras de capoeira" - mesmo se o seu 'sotaque' nessa linguagem corporal difira daquele de Baba, por nunca ter 'se convertido' num adepto da Capoeira Angola. Como escreve Clícia de Miranda no Anexo do livro, inserido logo depois da Apresentação: “O livro de Mestre Russo, mais do que uma obra biográfica e de contextualização da capoeira carioca, é uma mostra do poder de conhecimento que esta cultura permite [....] um conhecimento apreendido pela arte da cabeçada e da rasteira" (Almeida apud Russo de Caxias, 2005, p. 14). Mas é justamente aqui que reside a principal questão a ser elaborada: como figurar a relação entre tal conhecimento corporal e a composição do livro de Mestre Russo? Ou como tal relação é já configurada no livro? E importa salientar aqui que a questão é "como" e não "qual é" tal relação: pois tal relação consiste não num 'objeto' ou 'texto' a ser interpretado pelo antropólogo, mas numa figuração etnográfica e encorporada do sujeito antropográfico.

Além do deslocamento constante dos indícios da voz autoral e da constante substituição dessa voz por citações de outros textos e depoimentos das mais variadas fontes, o livro apresenta centenas de personagens de modos bastante distintos, desde a série de 'rememorações' dos ancestrais que já comentei, passando por cita- 
ções e comentários a respeito de Baden Powell, do tropicalismo, da proibição da capoeira, da censura cultural da Ditadura Militar. Não há nenhuma seção diretamente sobre a presença da mulher na roda, mas há uma seção contada em primeira pessoa da experiência de uma capoeirista mulher entrando na Roda Livre pela primeira vez e tocando o berimbau. ${ }^{6}$ Logo após a seção criticando a 'academização' da capoeira como um esporte disciplinado, citam-se várias longas passagens tiradas de teses acadêmicas que mencionam a Roda Livre. Para além dessas referências tão variadas entremeadas com histórias da roda de rua em si e do envolvimento do autor nessa roda, encontram-se, ainda, mais de cem fotos de capoeira e retratos de praticantes que frequentavam a roda - entre elas algumas de minhas fotografias.

Apresentado desse modo, o livro em questão parece até uma caricatura do comentário de Marilyn Strathern (2004, p. 10) de que "these days not all texts are intended to 'add up"" ("estes dias nem todos os textos 'se completam'"). Ela continua:

Textos que não se completam são supostamente encontrados nos gêneros pós-modernos que deliberadamente justapõem incomensuráveis narrativas. A constatação que completude é uma retórica em si mesma é incansavelmente exemplificada em colagem, ou coleções que não coletam mas exibem a intratabilidade de elementos díspares. [...] um tipo de acentuação de cortes de eventos percebidos, momentos, impressões. E se os elementos são apresentados como vários re-cortes, eles são inevitavelmente apresentados como partes oriundas de outros tecidos, de partes maiores em algum outro lugar (p. 11).

De fato, encontramos justamente uma colagem fotográfica de 64 retratos de capoeiristas (oito deles sendo de Mestre Russo) na página ao lado do Sumário com a longa lista de títulos das 37 seções do livro(!); assim localizada, a colagem poderia bem ser lida tanto como sinédoque quanto como metáfora do livro, cujas 'partes' são apresentadas mais linear e literalmente no Sumário ao lado. Mas aqui devemos entrar na 'roda' dessa comparação que as palavras de Strathern nos convidam a fazer com o livro de Mestre Russo com 
bastante precaução, contestando a crítica ali implicada. Primeiro, o livro de Mestre Russo certamente não foi escrito como um exemplar da literatura 'pós-moderna' - em que tal forma experimental de composição tornou-se certa convenção. Segundo, esse livro, como forma particular de colagem, é menos dirigido a um leitor qualquer que a pessoas que já têm alguma ligação 'fraternal' ou 'espiritual' com a capoeira (como dizia Baba acima) - não é por acaso que Mestre Russo costuma vender seu livro justamente nas rodas que frequenta. Desse modo, o conhecimento encorporado desses leitores já ajuda a 'saltar' entre as citações apresentadas no texto, sem mais explicações ou a constante presença de uma voz em terceira pessoa para interligar tais 'fragmentos'. E, terceiro, eu diria que as 'incomensuráveis narrativas' desse livro, mais do que 'deliberadas', são improvisadas ou, pelo menos, seu modo de textualização apela à própria natureza improvisada do jogo de capoeira e mais particularmente do "grupo de rua" que inaugurou a Roda Livre.

Para dar corpo a esta última afirmação, passo às palavras de Mestre Rogério (apud Russo de Caxias, 2005, p. 63), velho “companheiro de batalha" de Mestre Russo, cuja voz aparece várias vezes no livro:

Eu acho uma situação interessante com relação a nossa saída da academia do Mestre Barbosa, que foi um racha, e essa dissidência não virou um grupo de salão, mas virou um grupo de rua, que é um sistema livre de se organizar [...]. [E]ncontramos uma situação que não tinha leis determinadas, mas existia a Lei, cada um a trazia, sabia o que tinha que ser feito na roda de capoeira e cada um trazia o seu pedaço [...] e não existia, na verdade, na época, uma pessoa que dissesse 'é assim'; [...]. Não havia um Mestre entre nós, mas todos nós nos orientávamos em fazer a capoeira.

Note-se, de passagem, o aspecto um tanto radical de tal afirmação, no contexto da capoeira, considerando a quase obrigatoriedade de haver um mestre, segundo tantos mestres e praticantes, para os quais não haver um mestre costuma ser associado a uma renúncia à própria 'tradição' dessa arte. Mas nesse caso foi justamente um ato 
de dissidência com tal mestre que levou à formação dessa roda de Duque de Caxias, que se tornou, por sua vez, a roda certamente mais 'tradicional' no Rio de Janeiro, em grande parte por ter durado ou 'resistido' tanto tempo sem 'pertencer' a ninguém - o próprio Mestre Russo faz questão de ser chamado de 'zelador' (em vez de 'mestre') da Roda Livre. E foi essa própria roda de rua - como testemunham vários dos 'idealizadores' ou de 'expressões' da Roda Livre que eventualmente passou a 'formar' seus mais antigos participantes como reconhecidos 'mestres'.

Mas a descrição de Rogério faz algo mais do que apontar para a singularidade da 'história de vida' da Roda Livre. Quando lida como metáfora do próprio texto em que é inserido, sugere que Mestre Russo incorporou algo da 'forma livre' de expressão implicada naquela roda na própria composição de seu livro - assim como no devir de sua própria vida, como já discuti. Mais (ou menos) do que implicar várias outras 'partes' cortadas de outros lugares, e desse modo uma coleção de fragmentos que "não se completam" (Strathern, 2004, p. 10), as variadas partes e igualmente variados personagens dos quais o livro é composto implicam um constante movimento de recomposição assim como, com respeito à roda em si, cada componente "trazia o seu pedaço" que contribuía ao mesmo tempo com a 'Lei' da composição da roda em questão. E, quando o livro de Mestre Russo é lido dessa forma, como não só descrevendo ou se referindo ao jogo improvisado da Roda Livre, mas incorporando sua forma livre no próprio fluir do texto, saltando entre as partes das quais é composto, tal perspectiva envolve uma inversão de figura e fundo. Essa é uma inversão semelhante - mesmo que em sentido reverso - àquela da roda de leitura de uns dez anos atrás, tal como descrevi antes, que periodicamente substituía a nossa roda de capoeira no espaço improvisado na sede do Sindicato dos Petroleiros. Quando figurada nesse sentido, ressaltando o movimento 'encorporado' que anima o desdobrar do texto, é a própria Roda Livre - que não por acaso é quase sempre referida no livro com letras maiúsculas, assim como um nome próprio - que se torna o principal outro sujeito ativo (ver acima Wagner, 2001) do livro em questão, além de seu autor (ou, aliás, de seus leitores). 
Finalizando essa reflexão, chegamos à seguinte questão: se o livro de Mestre Russo for assim lido como um relato móvel - mas tudo menos linear - e dançante - mas também marcado por conflitos - da 'história da vida' da Roda Livre, então como é que tal vida narrada se relaciona com a antropologia do sujeito, tal como elaborada por Wagner?

Aqui, deixe-me retornar nossa atenção à segunda frase da Apresentação de Mestre Russo, só que dessa vez precedendo tal frase com uma de Wagner, como se fizessem parte da mesma reflexão:

Perceber o mundo como a reação do 'eu' ao mundo, é claro, é perceber um mundo refratado, defletido através do prisma do 'eu' (Wagner, 1991). Nesse volume serão encontrados fatos que me consolidaram como pessoa e que me deram estrutura suficiente para fazer da minha vivência na capoeiragem uma história que se revela em forma de documentário (Russo de Caxias, 2005, p. 10).

Lidas em conjunto, tais frases nos apontam para o enigma de como a 'pessoa' de Mestre Russo serviria tanto como projetor quanto como tela de tal "documentário" sobre "a história da capoeira em Duque de Caxias" (Russo de Caxias, 2005), como consta na frase anterior no livro em questão. Nesse sentido, a relação entre Mestre Russo, seu livro e a roda a que diz respeito envolveria um movimento giratório semelhante àquele já comentado anteriormente com respeito a Drawing Hands de Escher. Tal 'roda' poderia ser igualmente assemelhada aos desenhos dos Walbiri - e o "simbolismo humano" em geral -, tais como comentados por Wagner (1986, p. 23) em Symbols that Stand for Themselves, como envolvendo a transformação contínua entre "uma codificação simbólica artificialmente restrita" e "uma imagética icônica também artificialmente expandida".

Assim como anteriormente nos voltamos para o próprio desenho "autogerador" de Wagner que consta na capa de An Anthropology of the Subject, terminamos essa reflexão voltando-nos, enfim, para a imagem da capa da frente do livro de Mestre Russo. Pois, naquela imagem, pintada por um pintor que virou amigo de Mestre Russo, Aluysio Zaluar, encontramos outra figuração instigante de uma rodaem-movimento. 


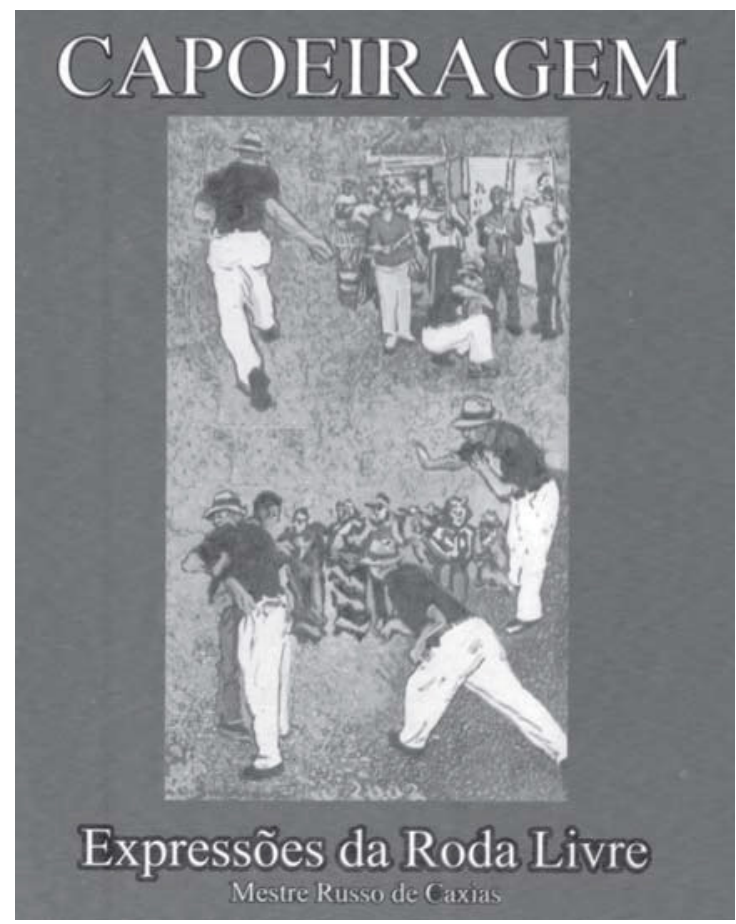

Figura 2 - Pintura de Aluysio Zaluar Fonte: Russo de Caxias, 2005, capa de frente.

O movimento em questão, na verdade, desdobra-se com respeito ao próprio movimento de Mestre Russo na roda da pintura: seu 'parceiro' (e oponente) no jogo só aparece em uma das cinco figurações do mestre na pintura. A roda, ela mesma, faz igualmente parte do movimento figurado na pintura, pois os seus dois 'lados' - se um círculo pode ter lados - encontram-se dobrados, ou desdobrados, um por cima do outro; desse modo, as duas perspectivas contrárias a dos músicos e a da audiência - são figuradas no mesmo plano de composição da pintura. Mas esse modo de figurar a roda em termos da mútua reversão dessa perspectiva face a face compõe algo como o fundo comum às figurações de Mestre Russo - essas parecendo deslocar-se no sentido horário.

Assim como o livro, a pintura em questão passa a "compreender" a perspectiva deste meu ensaio, desdobrando as partes que o compõem como também envolvidas numa roda de conexões mó- 
veis. A primeira figura de Mestre Russo na pintura é agachada ao 'pé do berimbau', no canto direito acima, em frente aos músicos, com seu braço parcialmente levantado indicando o início do movimento ou de 'entrada' na roda: essa é a introdução que também introduz indícios da 'pessoa' de Mestre Russo. A segunda figura mostra o mesmo mestre fazendo uma 'chamada na mandinga' que consiste em um 'jogo dentro do jogo' com suas próprias regras, ao mesmo tempo que faz parte do jogo; essa é o nosso parêntese teórico-figurativo sobre Drawing Hands de Escher e sobre como Wagner escreve de forma parecida. A terceira figura consiste num jogo em pé, com Mestre Russo "encarando" seu parceiro e oponente virtual na roda; foi assim que, no pequeno relato etnográfico da roda de leitura, Baba encarou de frente a pretensão de 'representar' a capoeira através da escrita sem ter 'laços fraternais' com o jogo em questão. A quarta imagem consiste no abraço que serve como conclusão do jogo, assim como busco aqui 'completar' o jogo deste ensaio - mas tome cuidado na hora de aproximar-se! E a quinta imagem (acima no canto esquerdo) é a própria pessoa de Mestre Russo saindo dessa ou qualquer outra figuração e levando a Roda Livre consigo para o mundo afora.

\section{Notas}

1 Início de um poema de Trinh T. Minh-ha (1989, p. 5): “me fizeram crer / que nós que escrevemos também dançamos / mas nenhum dançarino escreve / (da forma como escrevemos) / nenhum escritor dança / (assim como elas dançam)".

2 O que é um livro 'popular'? Tal adjetivo indica mais claramente o que não é do que o que é: no caso, não é um texto 'acadêmico' - como este, por exemplo. Mas tal distinção é capaz de confundir mais do que iluminar, na medida em que leva a pressupor que o primeiro seja necessariamente mais legível (readerly), no sentido dado por Barthes (1974) de se direcionar a uma leitura passiva em que o sentido do texto é tido como pré-constituído. Como veremos, o livro em questão assemelha-se mais ao que Barthes elabora como um texto escrevível (writerly), por prestar-se a múltiplas leituras e por demandar que o leitor contribua ativamente no tecer de seu significado.

3 Importa notar aqui que a 'antropografia', tal como conceituada por Jean-Paul Dumont (1986), envolve uma reflexividade voltada menos às interações do etnógrafo na situação de pesquisa do que ao próprio processo de escrever.

4 " $[. .$.$] the fact that no particular theoretical approach, even in combination with$ others, can be used effectively to gain a purchase over the anthropological subject."

\section{ILHA}

volume 12 - número 1 
5 Sherry Ortner (2007, p. 376) chega a afirmar que "o desenvolvimento da teoria social e cultural durante todo o século XX" poderia ser figurado "como uma luta sobre o papel do ser social - a pessoa, sujeito, ator ou agente - na sociedade e na história". Se assim for, a história do nosso sujeito mais especificamente antropológico e textual figura-se contra esse fundo sociológico e 'contextual' bem mais amplo de teorias do sujeito e afins.

6 Trata-se de Gegê, uma reconhecida capoeirista com quem eu mesmo já joguei em outras rodas, tanto no Rio quanto nos Estados Unidos. Com respeito à questão da 'mulher' no livro, há também outros indícios dispersos pelo livro que no mínimo marcam essa ausência apenas relativa - como umas poucas mulheres que constam nas fotos ou os comentários aqui e ali da esposa de Russo, que em certo momento diz: "Quando eu conheci o Jonas - Russo - sabia que ele era casado com a capoeira, aceitei ser sua amante e dei a ele dois filhos" (apud Russo de Caxias, 2005, p. 94).

\section{Referências}

BARTHES, Roland. S/Z. New York: Hill and Wang, 1974.

BATESON, Gregory. A Theory of Play and Fantasy. In: Steps to an

Ecology of the Mind. New York: Chandler Publishing, 1972. p. 177-193.

CLIFFORD, James; MARCUS, George (Orgs.). Writing Culture: The Poetics and Politics of Ethnography. Berkeley: University of California Press, 1986.

DUMONT, Jean-Paul. Prologue to Ethnography or Prolegomena to Anthropography. Ethos, v. 14, n. 4, p. 344- 365, Dec. 1986.

FERNANDEZ, James. Exploded Worlds: Text as a Metaphor for Ethnography (and Vice-Versa). Dialectical Anthropology, v. 10, n. 1, p. 15-27, 1985.

GEERTZ, Clifford. The Interpretation of Cultures. New York: Basic Books, 1973.

INGOLD, Tim. Lines: A Brief History. London: Routledge, 2007.

KAPFERER, Bruce. The Anthropologist as Hero: Three Exponents of Postmodernist Anthropology. Critique of Anthropology, v. 8, n. 2, p. 77-104, 1988.

ORTNER, Sherry. Subjetividade e crítica cultural. Horizontes Antropológicos, v. 13, n. 28, p. 375-405, 2007.

RICOEUR, Paul. The Model of the Text: Meaningful Action Considered as a Text. Social Research, v. 38, n. 3, p. 73-101, 1971.

RUSSO DE CAXIAS, Mestre. Capoeiragem: expressões da Roda Livre. Rio de Janeiro: Impresso, 2005.

STRATHERN, Marilyn. Partial Connections. Savage, MA: Rowman \& Littlefield Publishers Inc., 2004.

TAUSSIG, Michael. What do Drawings Want? Culture, Theory e Critique, v. 50, n. 2/3, p. 263-274, 2009.

\section{ILHA}

volume 12 - número 1 
TRINH, Minh-ha. Woman, Native, Other. Bloomington: Indiana University Press, 1989.

TURNER, Victor. Floresta de símbolos: aspectos do ritual Ndembu. Niterói: Ed. UFF, 2005.

WAGNER, Roy. The Invention of Culture. Chicago: University of Chicago Press, 1981. Press, 1986.

Symbols that Stand for Themselves. Chicago: University of Chicago 2001. . An Anthropology of the Subject. Berkeley: University of California Press, . A invenção da cultura. São Paulo: Cosac Naify, 2010a. . Coyote Anthropology. Lincoln, NB: Nebraska University Press, $2010 b$.

Recebido em: 29/09/201 1

Aceite em: 10/10/201 1 